\title{
Evaluation on Antioxidant Effect of Xanthohumol by Different Antioxidant Capacity Analytical Methods
}

\author{
Xiu-Li Zhang, ${ }^{1}$ Yong-Dong Zhang, ${ }^{1}$ Tao Wang, ${ }^{1}$ Hong-Yun Guo, \\ Qi-Ming Liu, ${ }^{2}$ and Hai-Xiang $\mathrm{Su}^{1}$ \\ ${ }^{1}$ Gansu Academic Institute for Medical Research, Lanzhou, Gansu 730050, China \\ ${ }^{2}$ Yumen Tuopu Scientific and Technological Development Co., Ltd., Yumen, Gansu 735000, China \\ Correspondence should be addressed to Hai-Xiang Su; haixiangsu@163.com
}

Received 29 January 2014; Revised 30 March 2014; Accepted 30 March 2014; Published 17 April 2014

Academic Editor: Li Ji

Copyright (C) 2014 Xiu-Li Zhang et al. This is an open access article distributed under the Creative Commons Attribution License, which permits unrestricted use, distribution, and reproduction in any medium, provided the original work is properly cited.

Several assays have been frequently used to estimate antioxidant capacities including ABTS ${ }^{\bullet+}$ DPPH, and FRAP assays. Xanthohumol $(\mathrm{XN})$, the major prenylated flavonoid contained in beer, witnessed various reports on its antioxidant capacity. We systematically evaluated the antioxidant activity of XN using three systems, 2,2,-azino-bis-3-ethylbenzthiazoline-6-sulphonic acid $\left(\mathrm{ABTS}^{\circ+}\right.$ ) scavenging assays, 1,1-diphenyl-2-picrylhydrazyl (DPPH) radical assays, and ferric reducing antioxidant power (FRAP) assays. The results are expressed as Trolox equivalent antioxidant capacity (TEAC). The TEAC of XN was $0.32 \pm 0.09 \mu \mathrm{mol} \cdot \mathrm{l}^{-1}$ by the ABTS assay and $0.27 \pm 0.04 \mu \mathrm{mol} \cdot \mathrm{l}^{-1}$ by the FRAP. Meanwhile, the XN did not show obviously scavenging effect on DPPH radical reaction system. These results showed that different methods in the evaluation of compound antioxidant capicity, there may be a different conclusion.

\section{Introduction}

Antioxidant capacity analysis is an important indicator to evaluate the antioxidation of the component. Several assays have been frequently used to estimate antioxidant capacity in free radical biology including 2,2,-azino-bis-3ethylbenzthiazoline-6-sulphonic acid $\left(\mathrm{ABTS}^{*+}\right)$ scavenging assays, 1,1-diphenyl-2-picrylhydrazyl (DPPH) radical assays, and ferric reducing antioxidant power (FRAP) assays. The difference of these methods is the use of different free radical. Xanthohumol $(\mathrm{XN})$ is a natural prenylated chalcone derived from hops (Humulus lupulus L.). Over the past decade, anticancer, antimutagenic, and anti-inflammatory [1-5] properties of XN have been studied by many researchers, and all of these biological properties are based on its antioxidant effect.

ROS play a crucial role in the pathogenesis of several human diseases, such as cancer, rheumatoid (rheumatoid) arthritis, neurodegenerative diseases, and pulmonary diseases [6]. It seems crucial to quench ROS as fast as possible before they attack biomolecules and cause harm. Antioxidants play an important role to eliminate ROS and other radicals; meanwhile, the antioxidant capacity is positively correlated with the ability of scavenging free radicals. There are many different kinds of evaluation reports for the antioxidant capacity of XN against ROS and other radicals. XN showed high antioxidant activity in inhibiting LDL oxidation [7], was able to scavenge reactive radicals including hydroxyl and peroxyl radicals, and inhibited superoxide anion and nitric oxide production [1]. However, it has also been reported that XN to be prooxidant, was able to rapidly induces $\mathrm{O}_{2}{ }^{--}$ [8]. In this paper, we compared with different methods for $\mathrm{XN}$ antioxidant capacity, to clarify whether methodology resulted in the conclusion differences. We have assessed the antioxidant capacity with attention to the following proposals: (1) Niki and Noguchi reported that there are two types of antioxidants that scavenge radicals quickly and quench many radicals, and they proposed assessing reactivity based on both reaction rate and stoichiometry [9]; (2) the activities of some antioxidants vary depending on the assay method, and thus use of multiple methods is recommended [9-12]; and (3) comparative studies using common antioxidants are essential to clarify the biological significance of the activities of sample. 
Trolox equivalent antioxidant capacity (TEAC) assay has been widely accepted for assessing "antioxidant power" as its inexpensive, highly reproducible, straightforward, and speedy procedure [13-16]. The TEAC method is based on the ability of antioxidant compounds to scavenge the longlived stable radical cation chromophore of 2,2-azinobis (3ethylbenzothiazoline 6-sulfonate; ABTS). Nowadays, TEAC value can be assigned to all compounds by comparing their scavenging capacity to that of Trolox, a water soluble vitamin E analogue [17], by several free radical reaction systems.

\section{Materials and Methods}

2.1. Chemicals. 2,2-Azinobis (3-ethylbenzothiazoline 6-sulfonate acid) diammonium salt (ABTS), 6-hydroxy-2,5,7,8tetramethylchromane-2-carboxylic acid (Trolox), hydrogen peroxide, 2,4,6-tripyridy-s-triazine (TPTZ), and 1,1-diphenyl-2-picrylhydrazyl (DPPH) were purchased from Sigma (ShangHai, Sigma, China). All chemicals were of analytical grade. Reagents were used without further purification. Milli-Q grade water was used in the whole process.

Xanthohumol was extracted from hop pellets (Humulus lupulus) in Yumen Tuopu Scientific and Technological Development Co. The briefly procedure as the following description. The purity was $98.64 \%$ by high performance liquid chromatography.

2.2. Sample Preparation. Stock solutions of each $\mathrm{XN}$ $\left(100 \mu \mathrm{g} \cdot \mathrm{mL}^{-1}\right)$ and Trolox $\left(1 \mathrm{mg} \cdot \mathrm{mL}^{-1}\right)$ were prepared in $100 \%\left(\mathrm{v} \cdot \mathrm{v}^{-1}\right)$ ethanol and stored at $-20 \pm 2^{\circ} \mathrm{C}$ until analysis.

2.3. Xanthohumol (Figure 1) Extraction and Isolation. The air-dried spent hop pellets (Humulus lupulus, $1.0 \mathrm{~kg}$ ) were extracted three times with $70 \%$ acetone in water at room temperature; after filtration and evaporation, the residue $(150 \mathrm{~g})$ was dissolved in water $(2.0 \mathrm{~L})$ and the solution was extracted three times by ethyl acetate (EtOAc) and N-butyl alcohol $(\mathrm{n}-\mathrm{BuOH})$, respectively. The EtOAc portion $(18 \mathrm{~g})$ was chromatographed on a silica gel column (200-300 mesh $170 \mathrm{~g})$ using $\mathrm{CHCl} 3: \mathrm{MeOH}(100: 1-2: 1)$ gradient to provide 7 fractions (Fr A-G). Fr C was subjected to column chromatography (CC), eluted with $\mathrm{CHCl} 3: \mathrm{MeOH}(100: 1-3: 1)$ to give five fractions ( $\mathrm{Fr} \mathrm{C1-C5).} \mathrm{Fr} \mathrm{C5} \mathrm{(1.5} \mathrm{g)} \mathrm{was} \mathrm{subjected} \mathrm{to} \mathrm{CC}$ eluted with petroleum ether: $\mathrm{CH} 3 \mathrm{COCH} 3(4: 1-2: 1)$ to give four fractions (C5-1-C5-4). C5-4 was subjected to CC eluted with petroleum ether: $\mathrm{CH} 3 \mathrm{COCH} 3(4: 1-2: 1)$ and then on a Sephadex LH-20 column ( $\mathrm{CHCl} 3: \mathrm{MeOH}, 2: 1)$ to obtain Xanthohumol (50 mg).

2.4. Measurement of XN Antioxidant Capacity. Three types of radical scavenging capacity analytical methods were employed in the study as the following description. Each concentration of XN was run in triplicate, respectively. Mean and standard deviation $(n=3)$ were calculated.

2.5. ABTS $^{\circ+}$ Radical Cation Scavenging Activity of XN. The assay is based on the inhibition of the absorbance of the

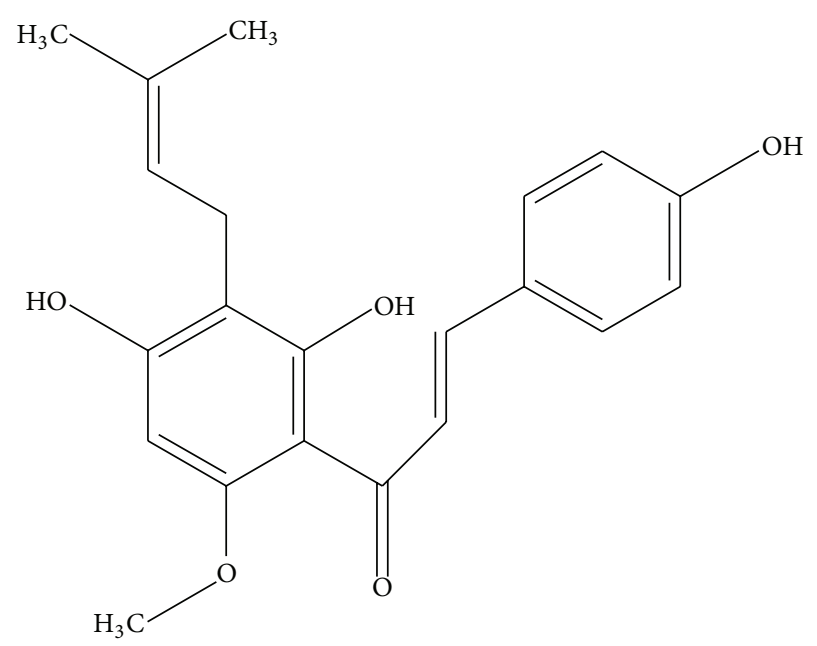

Figure 1: The molecular structure of Xanthohumol.

radical cation of 2,2-azinobis (3-ethylbenzothiazoline 6-sulfonate; ABTS) which has characteristic long-wavelength absorption spectrum showing maximum at $734 \mathrm{~nm}[17,18]$ slightly modified by Erel [19]. $150 \mu \mathrm{L}$ of ABTS test reagent $[17,18]$ and $50 \mu \mathrm{L}$ of sample were added to each well in a 96well microtiter plate. As unpaired electrons are sequestered by antioxidants in the sample, the ABTS test reagent turns colourless. The absorbance of reaction system at $734 \mathrm{~nm}$ with microplate reader is reduced. The percentage inhibition of $\mathrm{ABTS}^{\circ+}$ by the sample was calculated according to the following formula:

$$
\% \text { Inhibition }=\left[\frac{A_{0}-A_{i}}{A_{0}}\right] \times 100
$$

$A_{0}$ is the absorbance of the control, and $A_{i}$ is the absorbance of the sample.

The free radical scavenging capacity of the $\mathrm{XN}$, calculated as percentage inhibition of $\mathrm{ABTS}^{\circ+}$, was equated against a Trolox standard curve $\left(10-60 \mu \mathrm{mol} \cdot \mathrm{L}^{-1}\right)$. Results are expressed in TEAC $\left(\mu \mathrm{mol} \cdot \mathrm{L}^{-1}\right)$. Necessary dilution was done to ensure the ABTS value fell in the linear range of the standard curve.

2.6. $D P P H^{\bullet}$ Radical Scavenging Activity Assay of XN. The DPPH assay was performed according to the method developed by Brand-Williams et al. [20]. The percentage inhibition of $\mathrm{DPPH}^{*}$ by the sample was calculated according to the following formula:

$$
\% \text { Inhibition }=\left[\frac{A_{0}-A_{i}}{A_{0}}\right] \times 100
$$

$A_{0}$ is the absorbance of the control, and $A_{i}$ is the absorbance of the sample.

The free radical scavenging capacity of the $\mathrm{XN}$, calculated as percentage inhibition of $\mathrm{DPPH}^{\circ}$, was equated against 
a Trolox standard curve $\left(10-60 \mu \mathrm{mol} \cdot \mathrm{L}^{-1}\right)$. Results are expressed in TEAC concentration $\left(\mu \mathrm{mol} \cdot \mathrm{L}^{-1}\right)$. Necessary dilution was done to ensure the DPPH value fell in the linear range of the standard curve.

2.7. Ferric-Ion Reducing Antioxidant Power. A slightly modified FRAP method was used to test the total antioxidant capacity of XN [13]. In Benzie and Strain's original FRAP protocol $[13,21], 300 \mu \mathrm{L}$ of FRAP reagent and $40 \mu \mathrm{L}$ of sample were used in the reaction system. Half the amounts of FRAP reagent $(150 \mu \mathrm{L})$ and sample $(20 \mu \mathrm{L})$ were applied in this study to minimize the amount of sample needed to run the assay [22]. Briefly, the FRAP reagent was produced by mixing $300 \mathrm{mmol} \cdot \mathrm{L}^{-1}$ acetate buffer $(\mathrm{pH} \mathrm{3.6}), 10 \mathrm{mmol} \cdot \mathrm{L}^{-1} \mathrm{TPTZ}$ solution, and $20 \mathrm{mmol} \cdot \mathrm{L}^{-1} \mathrm{FeCl}_{3} \cdot 6 \mathrm{H}_{2} \mathrm{O}$ in a $10: 1: 1$ ration and was prepared freshly at $37^{\circ} \mathrm{C}[21,23,24]$. A total of $150 \mu \mathrm{L}$ of working FRAP reagent and $20 \mu \mathrm{L}$ of sample were added into each well in a 96-well microtiter plate and incubated at room temperature for $30 \mathrm{~min}$ in dark [25]. Reading of the colored product (ferrous tripyridyltriazine complex) was taken at $593 \mathrm{~nm}$ with microplate reader [22]. The Trolox standard curve was linear between 10 and $60 \mu \mathrm{mol} \cdot \mathrm{L}^{-1}$ Trolox. The initial blank reading for each well with just FRAP reagent was then subtracted from the final reading of FRAP reagent with sample to determine the FRAP value for sample [25]. Results are expressed in TEAC $\left(\mu \mathrm{mol} \cdot \mathrm{L}^{-1}\right)$. Necessary dilution was done to ensure the FRAP value fell in the linear range of the standard curve. Sample was measured in triplicate. Mean and standard deviation $(n=3)$ were calculated.

2.8. Statistical Analysis. All data are presented as means $( \pm \mathrm{SD})$ of at least three independent experiments, each experiment having a minimum of three replicates of sample. Student's paired $t$-test, correlation analyses, and linear regression analyses were performed using SPSS (version 13). The level of statistical significance was set at $P<0.05$ for two-side testing.

\section{Results and Discussion}

In the $\mathrm{ABTS}^{\circ+}$ radical cation scavenging assay system, the final concentrations of $\mathrm{XN}$ used in the analysis are 60, 50, 40, 30, 20, $10 \mu \mathrm{mol} \cdot \mathrm{L}^{-1}$ with $100 \%\left(\mathrm{v} \cdot \mathrm{v}^{-1}\right)$ ethanol, and there was significant linear correlation in the percentage inhibition of concentrations of the XN (15.1\%-47\%). The maximum inhibition was $47 \%$ at the concentration of $\mathrm{XN}$ being $60 \mu \mathrm{mol} \cdot \mathrm{L}^{-1}$. The calibration curve (Figure 2 ) revealed a highly positive linear $\left(R^{2}=0.999\right)$ correlation between the mean $\mathrm{ABTS}^{\circ}$ inhibition percentage and Trolox concentration. This curve was therefore employed to reliably estimate antioxidant potential of the tested samples, and the curve revealed a highly positive linear $\left(R^{2}=0.9821\right)$ correlation between mean $\mathrm{ABTS}^{\circ}$ inhibition percentage and concentration of $\mathrm{XN}$ too (Figure 3). The TEAC value of $\mathrm{XN}$ was $0.32 \pm 0.09 \mu \mathrm{mol} \cdot \mathrm{L}^{-1}$ by the ABTS assay (Table 1 ).

$\mathrm{DPPH}^{\circ}$ radical scavenging activity was quantified in terms of percentage inhibition of a preformed free radical by antioxidants in each sample. Trolox was used as standard antioxidant too. There was a highly positive linear
TABLE 1: TEAC values of XN as determined by $\mathrm{ABTS}^{\bullet+}, \mathrm{DPPH}^{\bullet}$, and FRAP.

\begin{tabular}{cccc}
\hline & ABTS $^{*+}$ & DPPH $^{\bullet}$ & FRAP \\
\hline TEAC & $0.31 \pm 0.09 \mu \mathrm{mol} \cdot \mathrm{L}^{-1}$ & - & $0.27 \pm 0.09 \mu \mathrm{mol} \cdot \mathrm{L}^{-1}$ \\
\hline
\end{tabular}

Data are expressed as mean \pm SD. Each assay was run three times $(n=3)$.

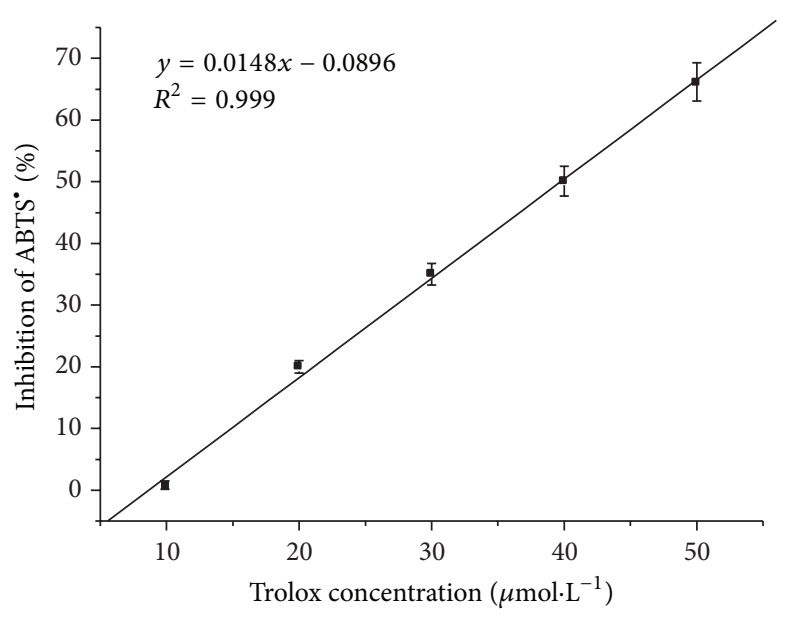

FIGURE 2: A representative calibration curve of $\mathrm{ABTS}^{\bullet+}$ inhibition by Trolox standards $\left(10,20,30,40,50 \mu \mathrm{mol} \cdot \mathrm{L}^{-1}\right) . Y=0.0148 x-0.0896$ and $R^{2}=0.999(n=3)$.

$\left(R^{2}=0.9968\right)$ correlation between the mean inhibition value and the Trolox concentration (Figure 4). However, there was no statistic signification on the inhibition $(10.7 \%-11.9 \%)$ of the $\mathrm{DPPH}^{\bullet}$ radical by the various concentrations of $\mathrm{XN}$ $\left(250,200,150,100,50 \mu \mathrm{mol} \cdot \mathrm{L}^{-1}\right.$ in $100 \%\left(\mathrm{v} \cdot \mathrm{v}^{-1}\right)$ ethanol) (Figure 5), with no clear linear correlation between the mean inhibition value and the XN concentration and no clear linear correlation between the mean inhibition value and the $\mathrm{XN}$ concentration $\left(R^{2}=0.6668\right)$.

The calibration curve (Figure 6 ) revealed a highly positive linear $\left(R^{2}=0.9992\right)$ relation between mean FRAP value and concentration of Trolox. Figure 7 showed the correlation between FRAP and XN concentrations (125, 100, 75, 50, $25 \mu \mathrm{mol} \cdot \mathrm{L}^{-1}$ in $100 \%\left(\mathrm{v} \cdot \mathrm{v}^{-1}\right)$ ethanol $)$, revealed a highly positive linear $\left(R^{2}=0.9938\right)$. The maximum FRAP value appeared at the $125 \mu \mathrm{mol} \cdot \mathrm{L}^{-1}$ of XN. The TEAC value of XN was $0.27 \pm 0.04 \mu \mathrm{mol} \cdot \mathrm{L}^{-1}$ by the FRAP (Table 1 ).

We evaluated the antioxidant capacity of XN by the TEAC assay through $\mathrm{ABTS}^{\circ+}$, $\mathrm{DPPH}^{\circ}$, and FRAP system and found significant difference for reducing ability of tested sample. Results showed that XN has stronger antioxidant activity in the $\mathrm{ABTS}^{\circ+}$ free radical inhibition and FRAP assay system. In the $\mathrm{ABTS}^{-+}$radical cation scavenging assay system, the $10 \mu \mathrm{mol} \cdot \mathrm{L}^{-1}$ of $\mathrm{XN}$ has $16.3 \%$ inhibition rate. The inhibition rate of $\mathrm{XN}$ reached $46.8 \%$ when its concentration was increased to $60 \mu \mathrm{mol} \cdot \mathrm{L}^{-1}$. There was a highly positive linear $\left(R^{2}=0.9839\right)$ correlation between mean inhibition value and concentrations of $\mathrm{XN}$ which showed that $\mathrm{XN}$ significantly 


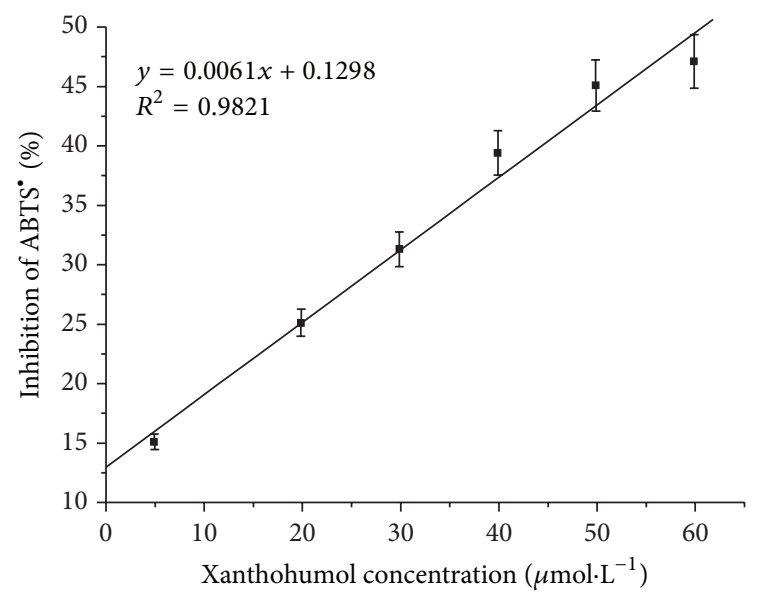

Figure 3: A linear correlation curve between Xanthohumol concentration and $\mathrm{ABTS}^{*+}$ inhibition percentage rate. $Y=0.0061 x+0.1298$ and $R^{2}=0.9821(n=3)$.

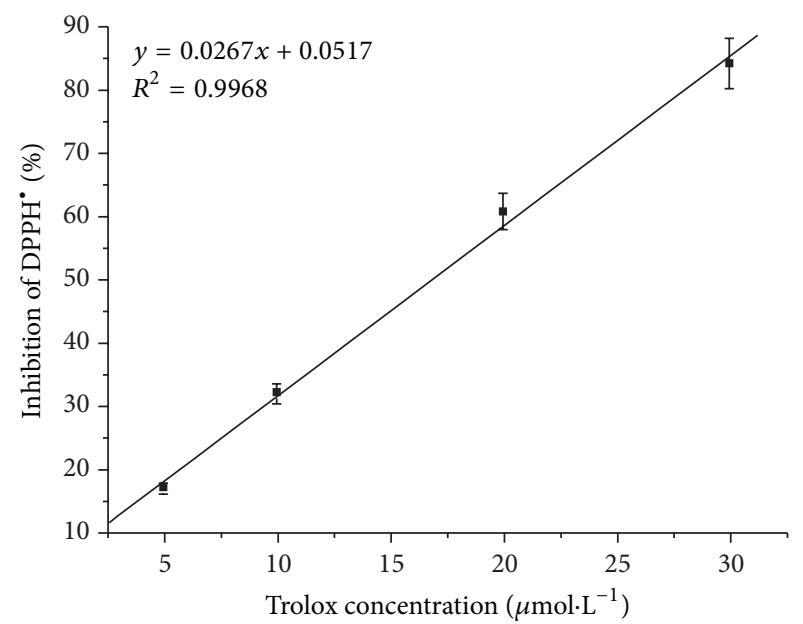

Figure 4: A representative calibration curve of inhibition $\mathrm{DPPH}^{\circ}$ by Trolox standards $\left(5,10,20,30 \mu \mathrm{mol} \cdot \mathrm{L}^{-1}\right) . Y=0.0267 x+0.0517$ and $R^{2}=0.9968(n=3)$.

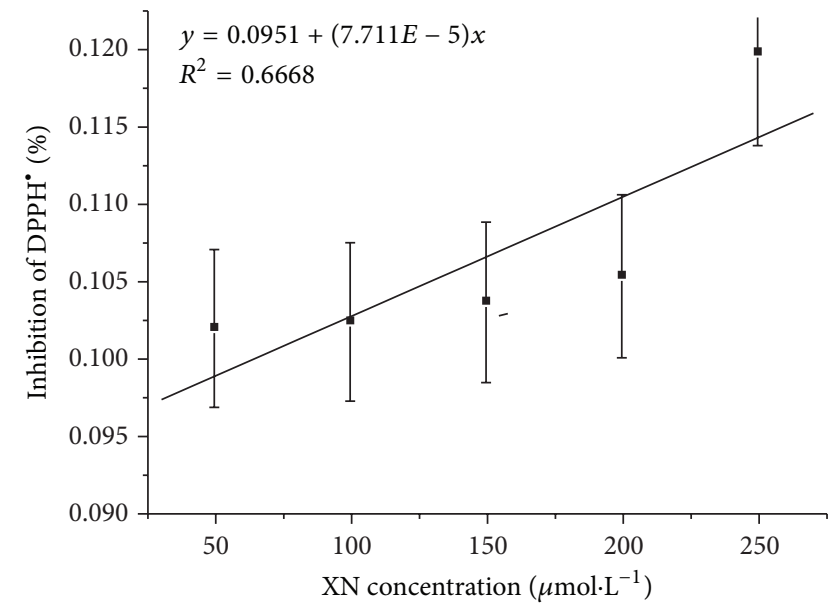

FIgURE 5: A linear correlation curve between Xanthohumol concentration and $\mathrm{DPPH}^{\circ}$ inhibition percentage rate. $Y=0.0951+$ $(7.711 E-5) X$ and $R^{2}=0.6668(n=3)$.

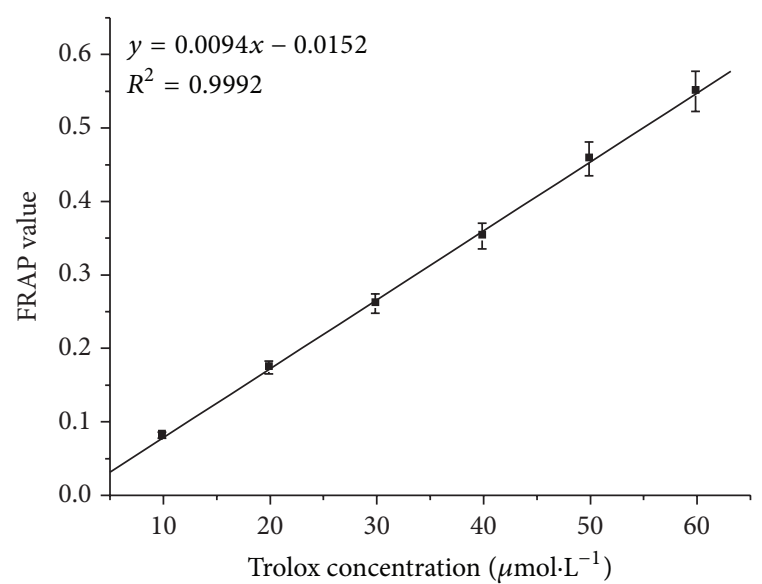

FIGURE 6: A representative calibration curve of FRAP values by Trolox standards $\left(10,20,30,40,50,60 \mu \mathrm{mol} \cdot \mathrm{L}^{-1}\right) . Y=0.0094 x-$ 0.0152 and $R^{2}=0.9992(n=3)$.

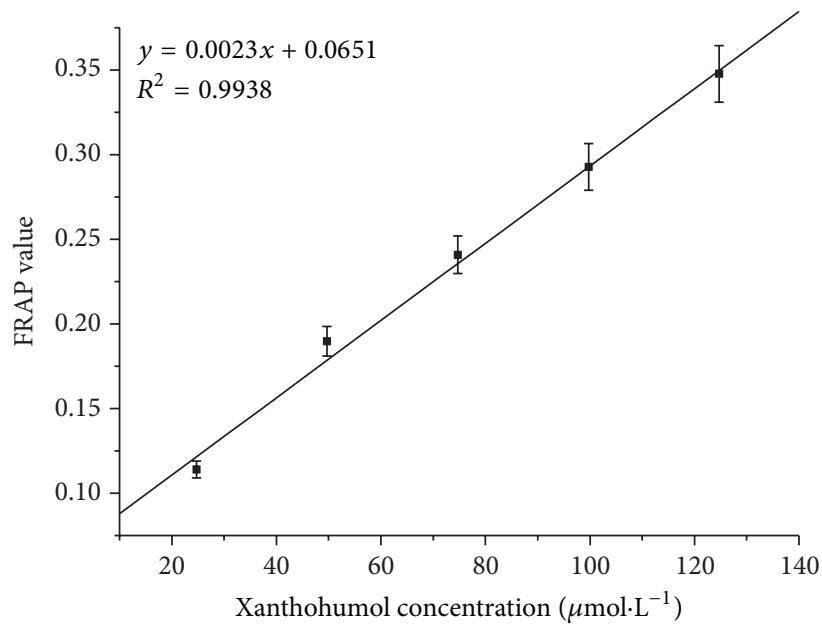

FIGURE 7: A representative calibration curve between Xanthohumol concentration and FRAP values percentage rate. $Y=0.0023 x+$ 0.0651 and $R^{2}=0.9938(n=3)$.

inhibited $\mathrm{ABTS}^{*+}$ in a concentration-dependent manner. Since FRAP measures the reduction of FeIII-TPTZ to FeIITPTZ, the reduction values were $49.2 \%, 42.3 \%, 37.2 \%, 31.5 \%$, and $23.5 \%$ with final concentrations of XN $(25,50,75,100$, and $\left.125 \mu \mathrm{mol} \cdot \mathrm{L}^{-1}\right)$. Comparing $\mathrm{ABTS}^{*+}$ with FRAP radical assay system, $\mathrm{XN}$ has stronger scavenging capacity in $\mathrm{ABTS}^{*+}$ than FRAP system. In the DPPH assay system, XN showed that the maximum inhibitory is $11.9 \%$ with any concentration of XN. Therefore, XN has no or little scavenging effect on DPPH radical cation. Danila et al. have reported that a DPPH does not react with flavonoids without substituted $\mathrm{OH}$ in the B-ring or with aromatic acids with a single $\mathrm{OH}$ group; consequently, it could be said that DPPH scavenging highly depends on the degree of electron delocalization in a structure-activity study [26, 27]. XN possesses $\mathrm{OH}$ phenolics in the B-ring. The Bors's found cannot be used to explain XN's weak DPPH free radical system scavenging effect therefore. The farther studies are needed to clarify the relationship 
between the structure of $\mathrm{XN}$ and its free radical scavenging capacity in DPPH assay system.

\section{Conclusion}

The findings of the present study based on different analytical principals suggest that the ABTS, DPPH, and FRAP assays gave comparable results for the antioxidant activity measured of $\mathrm{XN}$. XN is able to scavenge many types of ROS, has stronger free radical scavenging capacity in $\mathrm{ABTS}^{\circ+}$ than FRAP system, and has no or little scavenging effect on DPPH radical cation reaction. So, we need to pay attention to the choice of methods when evaluating the antioxidant capacity of XN.

\section{Conflict of Interests}

The authors declare that there is no conflict of interests regarding the publication of this paper.

\section{Acknowledgment}

This study was supported by the project supported by the Science-Technology Foundation for Middle-Aged and Young Scientists of Gansu Province, China, no.1170RJY031.

\section{References}

[1] C. Gerhauser, A. Alt, E. Heiss et al., "Cancer chemopreventive activity of Xanthohumol, a natural product derived from hop," Molecular Cancer Therapeutics, vol. 1, no. 11, pp. 959-969, 2002.

[2] C. Gerhäuser, "Beer constituents as potential cancer chemopreventive agents," European Journal of Cancer, vol. 41, no. 13, pp. 1941-1954, 2005.

[3] C. L. Miranda, Y. H. Yang, M. C. Henderson et al., "Prenylflavonoids from hops inhibit the metabolic activation of the carcinogenic heterocyclic amine 2-amino-3-methylimidazo[4,5f]quinoline, mediated by cDNA-expressed human CYP1A2," Drug Metabolism and Disposition, vol. 28, no. 11, pp. 1297-1302, 2000.

[4] R. Monteiro, C. Calhau, A. O. E. Silva et al., "Xanthohumol inhibits inflammatory factor production and angiogenesis in breast cancer xenografts," Journal of Cellular Biochemistry, vol. 104, no. 5, pp. 1699-1707, 2008.

[5] F. Ferk, W. W. Huber, M. Filipič et al., "Xanthohumol, a prenylated flavonoid contained in beer, prevents the induction of preneoplastic lesions and DNA damage in liver and colon induced by the heterocyclic aromatic amine amino-3-methylimidazo[4,5-f] quinoline (IQ)," Mutation Research - Fundamental and Molecular Mechanisms of Mutagenesis, vol. 691, no. 1-2, pp. 17-22, 2010.

[6] B. Halliwell and J. M. C. Gutteridge, Free Radicals in Biology and Medicine, Oxford University Press, New York, NY, USA, 3rd edition, 1999.

[7] C. L. Miranda, J. F. Stevens, V. Ivanov et al., "Antioxidant and prooxidant actions of prenylated and nonprenylated chalcones and flavanones in vitro," Journal of Agricultural and Food Chemistry, vol. 48, no. 9, pp. 3876-3884, 2000.

[8] J. Strathmann, K. Klimo, S. W. Sauer, J. G. Okun, J. H. M. Prehn, and C. Gerhäuser, "Xanthohumol-induced transient superoxide anion radical formation triggers cancer cells into apoptosis via a mitochondria-mediated mechanism," FASEB Journal, vol. 24, no. 8, pp. 2938-2950, 2010.

[9] E. Niki and N. Noguchi, "Evaluation of antioxidant capacity. What capacity is being measured by which method?" IUBMB Life, vol. 50, no. 4-5, pp. 323-329, 2000.

[10] K. Schlesier, M. Harwat, V. Böhm, and R. Bitsch, "Assessment of antioxidant activity by using different in vitro methods," Free Radical Research, vol. 36, no. 2, pp. 177-187, 2002.

[11] A. Janaszewska and G. Bartosz, "Assay of total antioxidant capacity: comparison of four methods as applied to human blood plasma," Scandinavian Journal of Clinical and Laboratory Investigation, vol. 62, no. 3, pp. 231-236, 2002.

[12] R. L. Prior and G. Cao, "In vivo total antioxidant capacity: comparison of different analytical methods," Free Radical Biology and Medicine, vol. 27, no. 11-12, pp. 1173-1181, 1999.

[13] I. F. F. Benzie and J. J. Strain, "The ferric reducing ability of plasma (FRAP) as a measure of "antioxidant power": the FRAP assay," Analytical Biochemistry, vol. 239, no. 1, pp. 70-76, 1996.

[14] G. Cao, C. P. Verdon, A. H. B. Wu, H. Wang, and R. L. Prior, "Automated assay of oxygen radical absorbance capacity with the COBAS FARA II," Clinical Chemistry, vol. 41, no. 12, pp. $1738-1744,1995$.

[15] N. J. Miller, C. Rice-Evans, M. J. Davies, V. Gopinathan, and A. Milner, "A novel method for measuring antioxidant capacity and its application to monitoring the antioxidant status in premature neonates," Clinical Science, vol. 84, no. 4, pp. 407-412, 1993.

[16] C. Rice-Evans and N. J. Miller, "Total antioxidant status in plasma and body fluids," Methods in Enzymology, vol. 234, pp. 279293, 1994.

[17] R. Re, N. Pellegrini, A. Proteggente, A. Pannala, M. Yang, and C. Rice-Evans, "Antioxidant activity applying an improved ABTS radical cation decolorization assay," Free Radical Biology and Medicine, vol. 26, no. 9-10, pp. 1231-1237, 1999.

[18] R. van den Berg, G. R. M. M. Haenen, H. Van Den Berg, and A. Bast, "Applicability of an improved Trolox equivalent antioxidant capacity (TEAC) assay for evaluation of antioxidant capacity measurements of mixtures," Food Chemistry, vol. 66, no. 4, pp. 511-517, 1999.

[19] O. Erel, "A novel automated direct measurement method for total antioxidant capacity using a new generation, more stable ABTS radical cation," Clinical Biochemistry, vol. 37, no. 4, pp. 277-285, 2004

[20] W. Brand-Williams, M. E. Cuvelier, and C. Berset, "Use of a free radical method to evaluate antioxidant activity," LWT-Food Science and Technology, vol. 28, no. 1, pp. 25-30, 1995.

[21] I. F. F. Benzie and J. J. Strain, "Ferric reducing/antioxidant power assay: direct measure of total antioxidant activity of biological fluids and modified version for simultaneous measurement of total antioxidant power and ascorbic acid concentration," Methods in Enzymology, vol. 299, pp. 15-27, 1998.

[22] K. Thaipong, U. Boonprakob, K. Crosby, L. Cisneros-Zevallos, and D. Hawkins Byrne, "Comparison of ABTS, DPPH, FRAP, and ORAC assays for estimating antioxidant activity from guava fruit extracts," Journal of Food Composition and Analysis, vol. 19, no. 6-7, pp. 669-675, 2006.

[23] C. Guo, J. Yang, J. Wei, Y. Li, J. Xu, and Y. Jiang, "Antioxidant activities of peel, pulp and seed fractions of common fruits as determined by FRAP assay," Nutrition Research, vol. 23, no. 12, pp. 1719-1726, 2003. 
[24] A. Jiménez-Escrig, M. Rincón, R. Pulido, and F. Saura-Calixto, "Guava fruit (Psidium guajava L.) as a new source of antioxidant dietary fiber," Journal of Agricultural and Food Chemistry, vol. 49, no. 11, pp. 5489-5493, 2001.

[25] S. P. Griffin and R. Bhagooli, "Measuring antioxidant potential in corals using the FRAP assay," Journal of Experimental Marine Biology and Ecology, vol. 302, no. 2, pp. 201-211, 2004.

[26] W. Bors, C. Michel, and K. Stettmaier, "Antioxidant effects of flavonoids," BioFactors, vol. 6, no. 4, pp. 399-402, 1997.

[27] A. O. Danila, F. Gatea, and G. L. Radu, "Polyphenol composition and antioxidant activity of selected medicinal herbs," Chemistry of Natural Compounds, vol. 47, no. 1, pp. 22-26, 2011. 

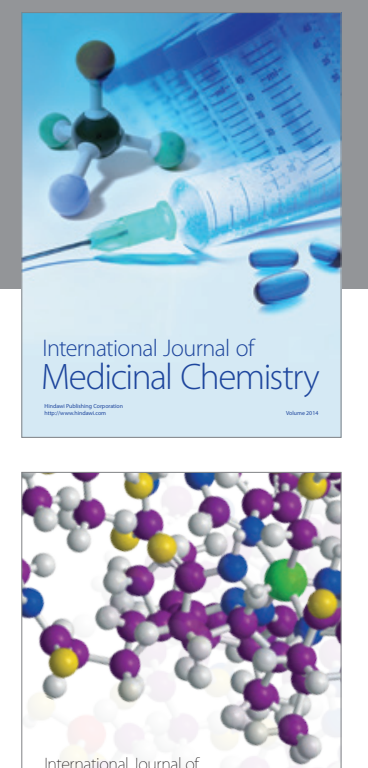

\section{Carbohydrate} Chemistry

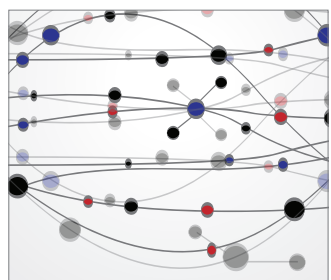

The Scientific World Journal
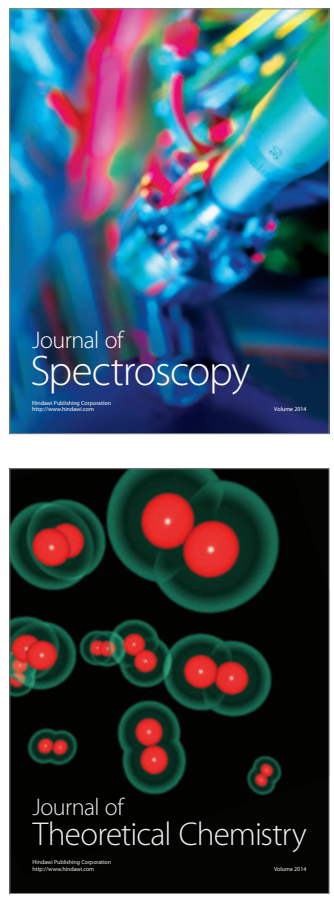
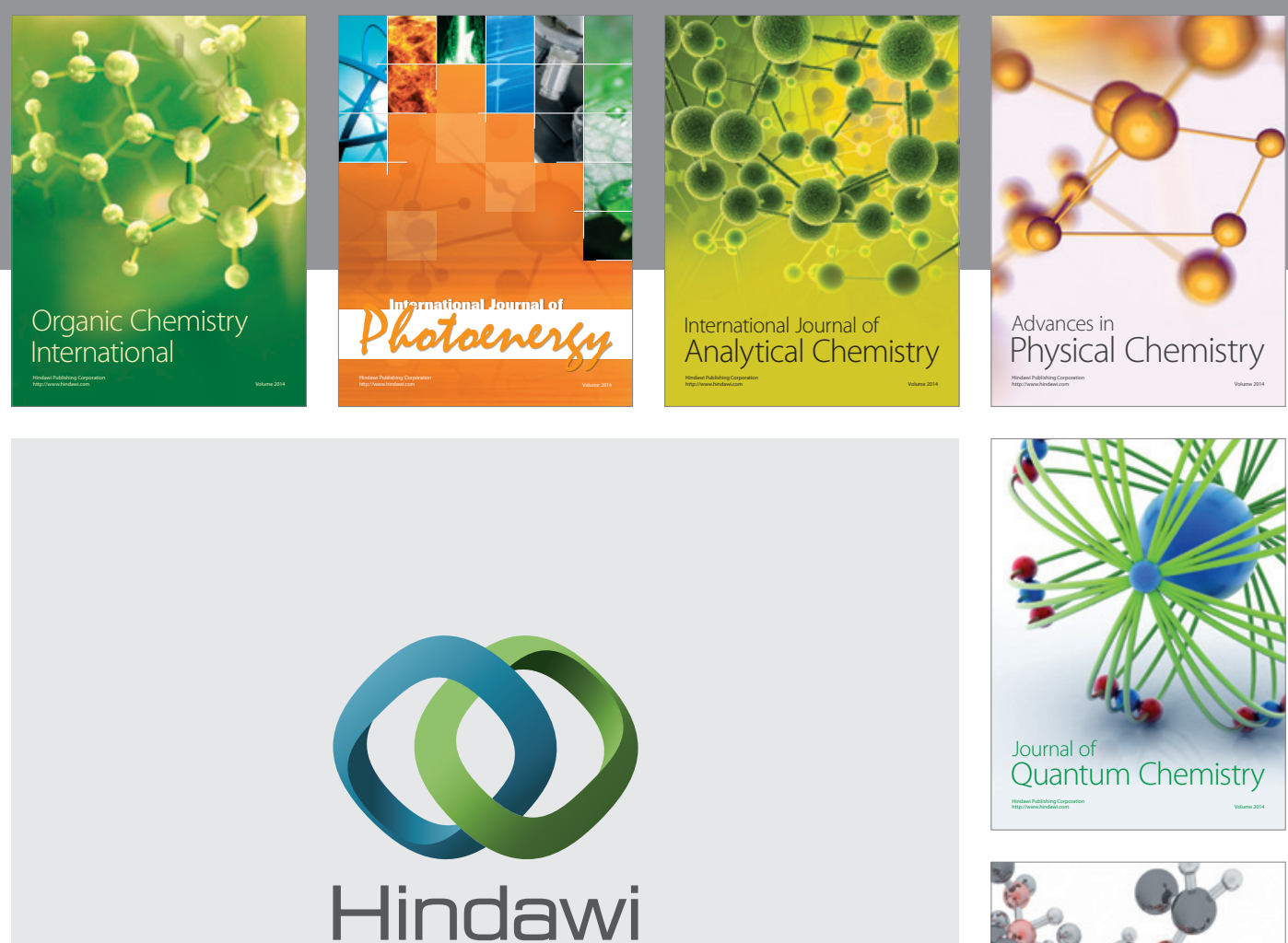

Submit your manuscripts at

http://www.hindawi.com

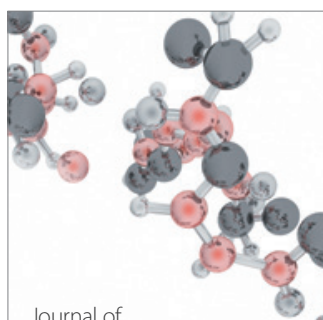

Analytical Methods

in Chemistry

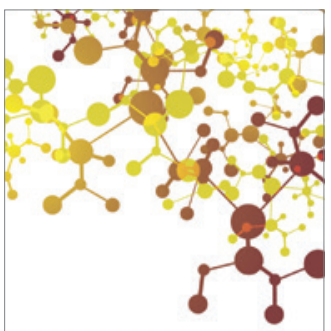

Journal of

Applied Chemistry

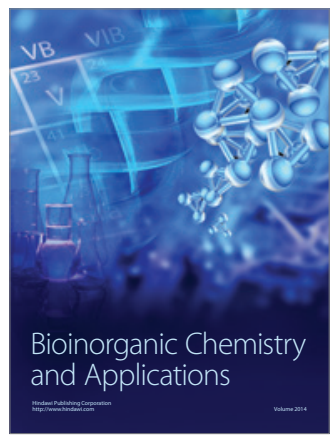

Inorganic Chemistry
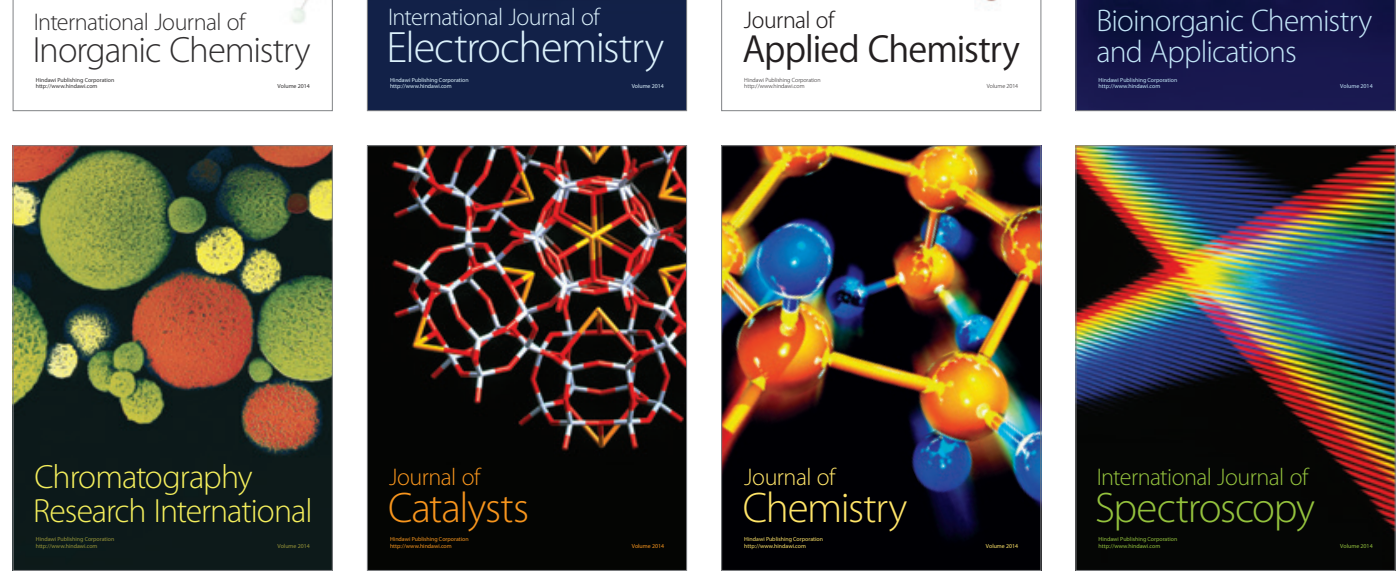